\title{
Analysis of Influencing Factors of Teaching Ability Development of Young Public Security College Teachers
}

\author{
Meng Wang \\ China Criminal Police University, Shenyang, P. R. China \\ mengwang@alum.imr.ac.cn
}

Keywords: Public Security College; Young teachers; Teaching ability; Influencing factors

\begin{abstract}
Cultivating objective of public security colleges is to transport high-quality probationary police officers with strong skills to front line of national public security, judicial and safeguarding departments. For young teachers undertaking the main teaching tasks, their teaching ability directly influences teaching quality of public security colleges and talent cultivation quality, so an emphasis must be laid on developing and improving teaching abilities of many young teachers.
\end{abstract}

\section{Introduction}

Teaching ability is prerequisite ability of a teacher to smoothly complete teaching activities. Teaching ability, which can be regarded as potential possibility of the teacher to reach teaching goal and obtain teaching effect, reflects direct and effective psychological features of individual teachers to smoothly complete teaching tasks. It is the most direct and obvious factor influencing teaching effect among various factors, as teaching ability of college teachers directly influences talent cultivation quality. Research on influencing factors of formation and development of teaching ability of public security college teachers is conductive to lay a foundation for how to elevate teaching ability of young public security college teachers.

\section{Analysis of Factors Influencing Teaching Ability Development of Young Public Security College Teachers}

Factors influencing formation and development of teaching ability of public security college teachers are quite complicated. A discourse will be made in this paper mainly from subjective and objective aspects.

Objective Factors. At present, position appointment system is basically implemented for teachers in regular colleges include public security colleges, under this system, if college teachers haven't had any scientific research achievement for three years, four years or longer period, it will be considered that they don't finish scientific research tasks, those in slight severe cases will be deducted with their subsidies and those in severe cases will have their professional titles degraded and even will be dismissed, but for young teachers occupied in heavy teaching tasks, they need to put major time and energy into teaching work, while realization of teaching achievements need long time and process, and recognition of teaching achievements is also difficult, so this system will certainly put young teachers engaged in teaching work in weak position in promotion through assessment. Teaching work can be quantified, but corresponding reasonable evaluation can't be made on its quality, and as a direct result, young teachers will transfer their effort emphasis to scientific research while neglecting elevation of teaching ability.

In teaching work in public security colleges, teaching hours can be quantified, but there is no objective standard evaluating teaching quality as teaching process is a long-term and continuously accumulated process. Teaching will not get instant results while scientific research results can be quantified and measured. Once scientific research project or expenditure acquired and articles published, numbers can certify academic achievements, while teaching can't be measured by number of students that one teacher teaches or scores obtained by students. Deficiency in teaching evaluation standard of young teachers will certainly affect teaching enthusiasm of young teachers.

Subjective Factors. Teaching is more an art than an ability of teachers. With continuously 
deepening reform of public security education in recent years, public security colleges have continuously stored talents with advanced scientific and cultural knowledge and technologies, but whether new teachers have scientific teaching skills and advanced teaching methods can't be comprehensively measured during recruitment process. Especially most young public security college teachers master's and doctor's degrees, but few of them graduate from normal colleges, and even some young teachers have never contacted basic knowledge like pedagogy and educational psychology, but instead, they directly act as front line teachers only after short-term and formalized pre-job training, lectures attending and trial lectures. Even though these have certain effects on teaching ability of young teachers, their effects are not obvious enough, and consequently, during realistic teaching process, young teachers usually don't know "what to teach" and "how to teach", they only repeat what the book says, and this will be bound to affecting knowledge-transference effect and classroom teaching quality.

Young public security college teachers are short of professional ethics, and this is also one aspect influencing their teaching ability. Teaching interest can influence one teacher's professional ethics, if teaching is out of the teacher's interest in public security teaching itself, what he focuses on is not only teaching effect but also utilization of teaching method and teaching aids during the whole teaching process. The reason why some young teachers select teaching cause in public security colleges is that they value relatively stable income in public security colleges but not out of their enthusiasm for public security education cause generated from inner heart.

\section{Approach to Improving Teaching Ability of Young Public Security College Teachers}

Promote Transformation of Teaching Ability of Young Teachers. On the $30^{\text {th }}$ Teacher's Day Symposium in Beijing Normal University, the general secretary-XI jinping pointed out that good teachers were not inborn, but they exercised and grew in teaching management practice and educational reform and development. Hence, it's necessary for department of human resource management of public security colleges to cooperate with teaching department and teaching teams wholeheartedly, create conditions for young teachers through multiple channels and approaches, facilitate continuous progress of young teachers, rapidly transform knowledge into teaching ability, and make it possible for many young teachers to become research-based backbone force as soon as possible.

Exert Promoting Effect of Teaching Teams. In nowadays society, individual force in one team has minor influence on the team, while overall joint force of the team can generate great influence on collective and society, and the influence is even subversive. For young teachers, transformation of their individual teaching abilities can't be realized within a short term, this transformation needs continuous accumulation and sedimentation of individual teachers for a long time, especially needs to be driven and promoted by teaching teams. Personnel management departments of public security colleges should keep up with teaching demand of teachers, accurately master characteristics and rules of teacher training management of public security colleges in the new period, and put efforts to facilitate rapid improvement of teaching abilities of teachers.

Always Persist in Implementing Lecture Attending System of Young Teachers. Lecture attending is a traditional way of improving teaching ability, but its effect on new young teachers is obvious. Hence, we should adhere to carefully implementing lecture attending system among young teachers. We should adopt multi-approach and multi-means of lecture attending system, expand lecture attending scope, and incorporate quality courses at all levels, college courses under key construction and courses undertaken by famous teaching masters. Moreover, we should encourage young teachers to carefully summarize experience from attending lectures, reflect on their own teaching situation, fish out a set of teaching methods appropriate for their own characteristics, gradually cultivate inclusive teaching styles of fine sense of humor, and let students be fond of attending classes and easily accept them.

Incorporate Teaching Ability and Quality into Teacher Performance Assessment. When assessing young teacher performance, departments of human resource management in public security colleges should place teaching and scientific research in the equally important positions 
and make comprehensive and balanced assessment from two aspects-teaching ability and scientific research level, but shall not catch one and lose the other. In young teacher assessment management of public security colleges, a phenomenon of stressing scientific research while neglecting teaching ability exists extensively, which directly results in deficiency of teaching enthusiasm among young teachers, and they put most energy into scientific research to prepare for professional title evaluation while being careless in teaching and thinking about teaching methods, so their teaching quality falls. In reality, excessive emphasis on scientific research quantity will also appear, value of scientific research achievements is nothing significant, and academic value is greatly discounted. Therefore, public security colleges should change the situation: taking pure supervision from teaching supervision teams and teaching workload as basis for evaluating teaching work. They should establish conventional long-acting administrative evaluation systems like assessing basic teaching abilities, updating of teaching contents and utilization of teaching methods of young teachers. Besides, for assessment of teaching abilities of young teachers, they should take consideration of teaching hours, teaching effect and scientific research achievements in teaching reform.

Create Favorable Campus Culture. Favorable campus culture can facilitate young teachers' acknowledgement of colleges, normalize teachers' behaviors, cohere teachers' strengths, stimulate dedication spirit of teachers, and improve their teaching abilities. Campus culture is an inimitable and irreplaceable intellectual impetus with college characteristics which can be established and completed only through preservation year after year. Young public security teachers have strong personalities and they stress self-growth and development, it's necessary to build people-oriented campus cultural atmosphere, and construction of favorable campus culture needs college administrators to provide favorable system guarantee, effective mechanism, correct policies and relaxing campus atmosphere for exertion of staff competence so as to enhance young teachers' enthusiasm and faith in teaching work, and in this way, they will give full play to their advantages and conti9nuously elevate their teaching level.

Establish Reasonable and Effective Incentive Mechanism. Departments of human resource management and educational administrative departments in public security colleges should cooperate in building and implementing incentive mechanism combining rewards and punishment. Based on reasonable evaluation on teaching effects, the incentive mechanism should openly commend young teachers with good teaching effects in a big way and provide them with opportunities to give lessons to in-service people's policemen training and attend inter-college and international exchanges, and besides, they can give bonus to these teachers as a way of encouragement. Moreover, teaching effect can also be listed as one of performance conditions in professional title appraisal of young teachers. Teachers with poor teaching effects and poor teaching evaluation should be appropriately punished so as to enhance their awareness of unexpected development and promote young teachers to continuously and proactively explore into paths for elevating their teaching abilities.

\section{Reference}

[1] Yang Dan, etc. Discussion on the Current Situation and Cultivating Routes of Teaching Ability College Young Teachers [J]. Industrial and Science Forum, 2015(14).

[2] Lucas R. E. On the Mechanics of Economics Development [J]. Journal of Monetary Economics, 2006, 22:5-40.

[3] He Jun. Research on The pattern of Human Resources Management of University Teachers in China from the Perspective of Independent Innovation [J]. Shanxi Education, Higher Education, 2013, 12:10-15 (In Chinese)

[4] D. E.Terpatra, A.A.Mohamed, E.J.Rozell.A Model of Human Resource Information, Practice Caoice, and Organizational Outcomes [J].Human Resource Management Review, 2007,4,56-67. 
[5] D.J.Storey. Education, Training and Development Policies and Practices in Medium-sized Companies in the UK: Do They Really Influence Firm Performance Omega, 2004, 30: 249-264

[6] Jagdish Bagwati. Auditing Chinese higher education? The perspectives of returnee scholars in an elite university, Imemational Joumal of Educational Development, 2011, 31(5):505-514.

[7] The Joint Task Force on Computing Curricula of ACM\IEEE. Computer Science Curricula 2013 Ironman Draft (Version 0.8 [EB/OL]. http://ai.stanford.edu/u sers/sahami/CS2013/,2015-07-26.

[8] John Wiley \& Sons, Inc. Strategic HR and Talent Management in Higher Education[J].ASHE Higher Education Report, 2012: 38, 1, 45-67.

[9] Lauder A, Sari R, Suwartha N, Tjahjono G. Critical review of a global campus sustainability ranking: Green Metric [J].Journal of Cleaner Production. 2015, 108: 852-863.

[10] Harvey L. Rankings of Higher Education Institutions: ACritical Review[J].Quality in Higher Education. 2008, 14(3): 187-207. 